\title{
EFFECT OF DIETARY TRANS FATTY ACIDS ON HIGH-DENSITY AND LOW-DENSITY LIPOPROTEIN CHOLESTEROL LEVELS IN HEALTHY SUBJEGTS
}

\author{
Ronald P. Mensink, Ph.D., and Martijn B. Katan, Phr.D.
}

Abstract Background. Fatty acids that contain a trans double bond are consumed in large amounts as hydrogenated oils, but their effects on serum lipoprotein levels are unknown.

Methods. We placed 34 women (mean age, 26 years) and 25 men (mean age, 25 years) on three mixed natural diets of identical nutrient composition, except that 10 percent of the daily energy intake was provided as oleic acid (which contains one cis double bond), trans isomers of oleic acid, or saturated fatty acids. The three diets were consumed for three weeks each, in random order:

Results. On the oleic acid diet, the mean ( $\pm S D$ ) serum values for the entire group for total, low-density lipoprotein (LDL), and high-density lipoprotein (HDL) cholesterol were $4.46 \pm 0.66,2.67 \pm 0.54$, and $1.42 \pm 0.32 \mathrm{mmol}$ per liter $(172 \pm 26,103 \pm 21$, and $55 \pm 12 \mathrm{mg}$ per deciliter), respectively. On the trans-fatty-acid diet, the subjects' mean HDL

$\mathrm{R}$ ECENT studies have emphasized the importance of monounsaturated fatty acids in reducing saturated-fat intake and thereby lowering the serum level of the atherogenic low-density lipoprotein (LDL) cholesterol. 1,2 These studies have focused on oleic acid, a monounsaturated fatty acid with the cis configuration; however, many foods also contain trans fatty acids. These are unsaturated fatty acids in which the carbon moieties on the two sides of a double bond point in opposite directions. Most natural fats and oils contain only cis double bonds, in which the carbon moieties lie on the same side' (Fig. 1). Trans fatty acids are found in small amounts in the fats of ruminants; for example, $100 \mathrm{~g}$ of milk fat contains 4 to $8 \mathrm{~g}$ of trans fatty acids. ${ }^{3}$ Much larger amounts are found in certain types of margarines, margarine-based products, shortenings, and fats used for frying.,5 These trans fatty acids are formed when vegetable and marine oils, rich in polyunsaturated fatty acids, are hardened by a process called hydrogenation to produce fats that have the firmness and plasticity desired by food manufacturers and consumers. ${ }^{6}$ The estimated average daily intake of trans fatty acids is 8 to $10 \mathrm{~g}$, or 6 to 8 percent of total daily fat consumption, in the United States ${ }^{7}$ and $17 \mathrm{~g}$ in the Netherlands. ${ }^{8}$ Intake may be much higher in persons who eat large amounts of hard fats and margarines or foods prepared with or fried in such fats. The pressure to reduce the use of saturated tropical fats such as palm oil may cause an increase in the consumption of trans fatty acids; because for the ed-

From the Department of Human Nutrition, Agricultural University, Bomenweg 2, 6703 HD Wageningen, the Netherlands, where reprint requests should be addressed to Dr. Katan.

Supported by the Netherlands Nutrition Foundation, the Netherlands Ministry of Welfare, Public Health, and Cultural Affairs, and the Commission of the European Communities. Dr. Mensink is a Dr. Dekker Fellow of the Netherlands Heart Foundation (grant D-87002). cholesterol level was $0.17 \mathrm{mmol}$ per liter $(7 \mathrm{mg}$ per deciliter) lower than the mean value on the diet high in oleic acid $(P<0.0001 ; 95$ percent confidence interval, 0.13 to 0.20 mmol per liter). The HDL cholesterol level on the saturated-fat diet was the same as on the oleic acid diet. The LDL cholesterol level was $0.37 \mathrm{mmol}$ per liter $(14 \mathrm{mg}$ per deciliter) higher on the trans-fatty-acid diet than on the oleic acid diet $(P<0.0001 ; 95$ percent confidence interval, 0.28 to $0.45 \mathrm{mmol}$ per liter) and $0.47 \mathrm{mmol}$ per liter $(18 \mathrm{mg}$ per deciliter) higher on the saturated-fat diet $(P<0.0001 ; 95$ percent confidence interval, 0.39 to $0.55 \mathrm{mmol}$ per liter) than on the oleic acid diet. The effects on lipoprotein levels did not differ between women and men.

Conclusions. The effect of trans fatty acids on the serum lipoprotein profile is at least as unfavorable as that of the cholesterol-raising saturated fatty acids; because they not only raise LDL cholesterol levels but also lower $\mathrm{HDL}$ cholesterol levels. (N Engl J Med 1990; 323:439-45.)

ible-fat industry they are the best alternative to saturated fatty acids for the production of semisolid and solid fats.

'The most abundant trans fatty acids in the diet are elaidic acid and its isomers, ${ }^{7}$ which are fatty acids with 18 carbon atoms and one double bond (Fig. 1). Two studies suggested that these trans fatty acids, as compared with their cis isomer oleic acid, elevate serum total cholesterol levels. ${ }^{9,10}$ However, this effect was not confirmed in a third study. "We have now studied the effects of trans fatty acids - specifically, elaidic acid and its isomers - on serum lipoprotein and apolipoprotein levels in healthy women and men.

\section{Methods}

\section{Subjects}

Forty-eight women and 27 men, most of them students, applied for enrollment in the study. None had a history of atherosclerotic disease, and all were apparently healthy, as indicated by the results of a medical questionnaire. None had anemia, glycosuria; or proteinuria. One woman was being treated for hypertension with a $\beta$-adrenergic blocking agent; none of the other subjects were taking medication known to affect serum lipids. The protocol and goals of the study were fully explained to the subjects, who gave their written consent. No payment was given, except the free food in the study diets. Approval for the study had previously been obtained from the ethics committee of the department.

We accepted all 27 men. Because only 62 subjects could participate, we then added 1 woman who was married to a participant and selected another 34 women at random. They included the woman with hypertension, who did not change the dosage of her medicine throughout the study. One woman and two men withdrew before the study began. Thus, 25 men and 34 women started the study, and all finished it successfully. Before the beginning of the study diets, the subjects' fasting serum lipid levels ranged from 3.40 to 7.15 mmol per liter (mean, $4.75 \mathrm{mmol}$ per liter [184 $\mathrm{mg}$ per deciliter]) for total cholesterol, from 0.63 to $2.38 \mathrm{mmol}$ per liter (mean; $1.30 \mathrm{mmol}$ per liter [50 mg per deciliter]) for high-density lipoprotein (HDL) cholesterol, and from 0.36 to $2.54 \mathrm{mmol}$ per liter (mean, $0.96 \mathrm{mmol}$ per liter. [85 mg per deciliter]) for triglycerides.

The men were between 19 and 52 years of age (mean, 25). They 


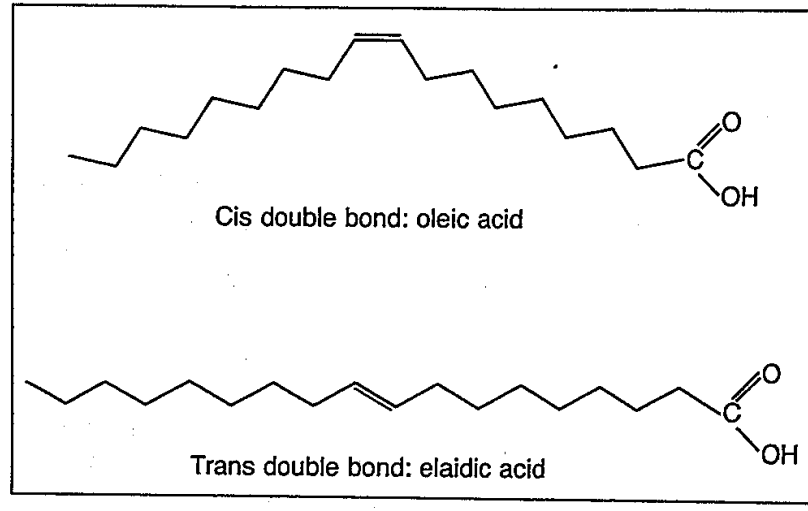

Figure 1. Structure of Cis and Trans Fatty Acids.

Cis double bonds produce a bend in the molecule that impairs crystallization and keeps the oil liquid. To convert vegetable and marine oils into fats of various degrees of plasticity, manufacturers of edible fat straighten out cis unsaturated fatty acids by converting them to trans isomers or saturated fatty acids in a process called hydrogenation.

weighed 65 to $87 \mathrm{~kg}$ (mean, 75) and their body-mass index (the weight in kilograms divided by the square of the height in meters) ranged from 18.4 to 25.4 (mean, 22.0). The women were between 19 and 57 years of age (mean, 26). They weighed 54 to $90 \mathrm{~kg}$ (mean, 64 ), and their body-mass index ranged from 17.4 to 29.7 (mean, 22.0 ). Eight women used oral contraceptives, and two women, but none of the men, smoked.

\section{Design and Statistical Analysis}

Each participant followed the three diets for three weeks each, with no washout period between the diets. In our experience, serum lipoprotein levels stabilize within two weeks after a dietary change. ${ }^{12,13}$ One diet was high in oleic acid, another a dietary change. One diet was high in oleic acid, another high in trans isomers of oleic acid, and the third high in saturated fat, notably lauric acid (C12:0) and palmitic acid (C16:0). Before the study began, the subjects were categorized according to sex, and women were also categorized according to the use of oral contraceptives. The subjects were then randomly divided into six groups so that each group had a nearly identical number of subjects from each category. Each group then received the diets in a different order In this way, variation duc to residual effects of the previous diet or to the drift of variables over time could be assessed and elimi nated. ${ }^{14}$

The data were analyzed with the General Linear Models procedure of the Statistical Analysis System. ${ }^{15}$ When the analysis indicat ed a significant effect of a diet $(P<0.05)$, the Bonferroni method was used for a pairwise comparison of the diets. Since this procedure involved three simultaneous comparisons, the upper limit of statistical significance was set at one third of the customary level of 0.05 - i.e., 0.017. All $P$ values are two-tailed.

\section{Diets}

Before the study began, the subjects weighed their food and recorded their habitual diet for two working days and one weekend day to allow us to estimate their energy and nutrient intake. The food records were coded and the composition of the diets calculated with use of the 1986 edition of the Netherlands Nutrient Data
Base. ${ }^{16}$

The diets followed during the study consisted of conventional solid foods, and the menus were changed daily during each threeweek cycle. The nutrient content of the three diets was similar, except for 10 percent of total energy, which was provided by oleic acid, trans isomers of oleic acid, or saturated fatty acids. The oleic acid group received special bread enriched with olive ojil and a margarine made of a variety of sunflower oil high in oleic acid (Trisun, SVO Enterprises, Wickliffe, Ohio). This oleic acid-rich sunflower oil made up 85 percent of the fat in the margarine: the remaining 15 percent was composed of equal volumes of lightly hydrogenated palm oil and palm-kernel oil that were mixed and then interesterified. The sunflower oil contributed 45 percent of all monounsaturated fatty acids in the oleic acid diet, olive oil contrib. uted 21 percent, and rapeseed oil low in erucic acid, 10 percence the trans-fatty-acid diet, the same olcic acid-rich sunflower oil was isomerized so that half the oleic acid molecules were converted to the trans configuration, while avoiding the isomerization of linolec acid (Table 1). Seventy-eight parts of this hydrogenated fat were subsequently mixed with 10 parts of the unaltered oleic acid-rich sunflower oil, 10 parts of regular sunflower oil, and 2 parts of rapeseed oil low in erucic acid, yielding a margarine and a shorten. ing with high levels of trans fatty acids. This shortening was also used to prepare a special bread containing $8 \mathrm{~g}$ of shortening per $100 \mathrm{~g}$. The saturated-fat diet included another special kind of margarine and shortening, this one high in lauric acid and palmitic acid (Table 1). These fats were made by interesterifying 24.5 parts of lightly hydrogenated palm oil and 35.5 parts of lightly hydrogen. ated palm-kernel oil. This mixture was then added to 40 parts of the oleic acid-rich sunflower oil to prepare the shortening and margarine. The special fats and margarines were developed and manufactured by the Unilever Research Laboratory (Vlaardingen, the Netherlands). Other typical items consumed during the study wett bread, full-fat cheese, low-fat meat for sandwiches, milk or yogur (low-fat varieties were used for the oleic acid and trans-fatllacid diets), fruit, cookies, jam or honey, potatoes, cooked vegt. tables, salad garnished with egg yolk, gravy, and occasionally, an egg.

The diets were formulated at 28 levels of energy intake ranging from 5.5 to $20.0 \mathrm{MJ}$ (1315 to $4780 \mathrm{kcal})$ per day. The intake of protein, carbohydrates, alcohol, cholesterol, and dietary fiber did not differ among the diets. In addition, the consumption of the various saturated and polyunsaturated fatty acids was the same on the trans-fatty-acid diet as on the oleic acid diet (Table 2).

All fondstuffs were weighed for each subject. On weekdays at noon, hot meals were served in the department and eaten in our presence. All other food was provided daily as a package. Food for the weekend and guidelines for its preparation were provided each Friday. In addition to the foods supplied, the subjects were allowed to eat a limited number of items free of fat and cholesterol. These free-choice items were listed and accorded points corresponding to their-energy values, with one point equaling $41.8 \mathrm{~kJ}(10 \mathrm{kcal})$. Each subject was required to consume daily food totaling a specific number of points that varied slightly with energy intake and ranged from 7 to 11 percent of the total daily energy intake. The subjects were urged not to change their selection of free-choice items between diet periods.

The subjects were asked to maintain their usual patterns of activity, smoking habits, and use of oral contraceptives. They recorded in diaries any sign of illness, medications used, the free-choice items selected, and any deviations from their diets. Inspection of the diaries did not reveal any deviations from the protocol that might have affected the results.

Duplicate portions of each diet for one imaginary participant with a daily energy intake of $10 \mathrm{MJ}(2390 \mathrm{kcal})$ were collected during each of the three periods, stored at $-20^{\circ} \mathrm{C}$, pooled according to diet, and analyzed after the study. The free-choice items consumed were coded, and their composition was calculated with use of the Netherlands Nutrient Data Base. 16 The analyzed values of the duplicate diets were combined with the calculated values for the free-choice items (Table 2).

Body weights without shoes or heavy clothing were recorded twice a week, and energy intake was adjusted when necessary. During the 63 days of the study, the average body weight $( \pm \mathrm{SD}) \mathrm{de}$ creased by $0.1 \pm 1.0 \mathrm{~kg}$ (range, -2.2 to 2.7 ), but this decrease was not attributable to a specific diet.

\section{Blood Sampling and Analysis}

Before the study all subjects were assigned a random number that was then used for labeling blood and serum or plasma tubes. In this 
Table 1. Fatty-Acid Composition of the Margarines Used in the Three Diets.

\begin{tabular}{|c|c|c|c|}
\hline FATTY ACID & $\begin{array}{l}\text { OLEIC ACID } \\
\text { DIET }\end{array}$ & $\begin{array}{c}\text { Trans-FatTy- } \\
\text { ACID DIET }\end{array}$ & $\begin{array}{l}\text { Saturated- } \\
\text { FAt Diet }\end{array}$ \\
\hline$\therefore \ldots 1 \ldots$ & \multicolumn{3}{|c|}{ ğrams per $100 \mathrm{~g}$ of fatty acid } \\
\hline $\begin{array}{l}\text { Saturated } \\
\text { Lauric acid (C12:0) } \\
\text { Myristic acid (C14:0) } \\
\text { Palmitic acid (C16:0) } \\
\text { Stearic acid (C18:0) }\end{array}$ & $\begin{array}{r}22.5 \\
2.7 \\
1.5 \\
6.6 \\
9.6\end{array}$ & $\begin{array}{r}13.3 \\
0.2 \\
0.1 \\
3.9 \\
7.2\end{array}$ & $\begin{array}{r}44.0 \\
14.2 \\
5.4 \\
15.4 \\
6.2\end{array}$ \\
\hline $\begin{array}{l}\text { Monounsaturated } \\
\text { Cis-C18:1 } \\
\text { Trans-C18:1 }\end{array}$ & $\begin{array}{r}71.1 \\
70.7 \\
0.3\end{array}$ & $\begin{array}{l}77.7 \\
32.1 * \\
45.8 \dagger\end{array}$ & $\begin{array}{r}48.6 \\
47.9 \\
0.6\end{array}$ \\
\hline $\begin{array}{l}\text { Polyunsaturated } \\
\text { Linoleic acid (cis-cis-C18:2) }\end{array}$ & $\begin{array}{l}6.5 \\
6.2\end{array}$ & $\begin{array}{l}8.1 \\
7.8\end{array}$ & $\begin{array}{l}7.8 \\
7.4\end{array}$ \\
\hline Others & 0.1 & 1.1 & 0.0 \\
\hline
\end{tabular}

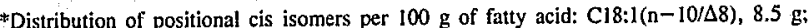

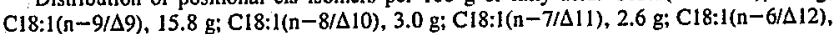
$1.2 \mathrm{~g}: \mathrm{C} 18: 1(\mathrm{n}-5 / \Delta 13), 0.6 \mathrm{~g}$; and $\mathrm{C} 18: 1(\mathrm{n}-4 / \Delta 14), 0.3 \mathrm{~g}$.

iDistribution of positional trans isomers per $100 \mathrm{~g}$ of fatty acid: $\mathrm{Cl} 8:[(\mathrm{n}-12 / \Delta 6), 0.3 \mathrm{~g}$

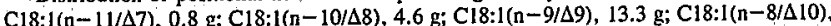

$10.6 \mathrm{~g} ; \mathrm{Cl} 8: 1(\mathrm{n}-7 / \Delta 11), 9.4 \mathrm{~g}$; and $\mathrm{Cl} 8: 1(\mathrm{n}-6 / \Delta 12), 6.7 \mathrm{~g}$.

way, the technicians who performed the chemical analyses were unaware of the subjects' diet sequence.

Blood was sampled after an overnight fast on days 1,18 , and 21 (period 1), days 39 and 42 (period 2), and days 60 and 63 (period 3). Serum was obtained by low-speed centrifugation, stored at $-80^{\circ} \mathrm{C}$, and analyzed enzymatically for total and HDL cholesterol and triglyceride levels at the end of the study. ${ }^{18,19}$ All the samples from each subject were analyzed in one run. The coefficient of variation within one run for control serum samples was 0.9 percent for total cholesterol, 1.3 percent for HDL cholesterol, and 1.7 percent for triglycerides. Accuracy was checked by the analysis of three serum pools of known value provided by the Centers for Disease Control (Atlanta) and, for HDL cholesterol only, of three pools provided by the North-West Lipid Research Clinic. ${ }^{20}$ The mean bias with regard to target values of the Centers for Disease Control pools was 0.01 mmol per liter for total cholesterol and $0.08 \mathrm{mmol}$ per liter for total triglycerides. The mean bias with regard to the target value of the North-West Lipid Research Clinic pools for HDL cholesterol was $-0.06 \mathrm{mmol}$ per liter. The LDL cholesterol concentration was calculated with use of the Friedewald equation. ${ }^{21}$ The two lipoprotein values obtained at the end of each dietary period were averaged for data analyses.

For each subject, the fatty-acid composition of erythrocyte membranes was determined in duplicate in samples obtained at the end of each dietary period (days 21, 42, and 63), as described earlier, except that we used a capillary Sil-88 column. ${ }^{22}$ The results were expressed as a proportion by weight of all fatty acids detected. For the apolipoprotein analyses, equal volumes of the two plasma samples obtained at the end of each dietary period were pooled. Apolipoprotein A-I was measured by immunoturbidimetry, ${ }^{23}$ with sheep antiserum. Apolipoprotein B was measured in plasma in all samples by radial immunodiffusion with antiserum raised in goats. ${ }^{24}$ All samples for each subject were analyzed in duplicate on the same plate, and the results of each diet period were averaged. The secondary calibration pools for apolipoprotein B were calibrated with the use of a pool of known value provided by the Centers for Disease Control (Pool IUIS/NHLBI/CDC 1883) as the primary standard. The coefficient of variation within one run was 2.5 percent for apolipoprotein A-I and 3.9 percent for apolipoprotein B.

\section{Results}

The mean daily intakes of energy and nutrients on the three experimental diets are shown in Table 2. Total fat and cholesterol intakes did not differ among diets during the study. The percentage of total energy from oleic acid decreased from 23.0 percent on the oleic acid diet to 12.6 percent on the trans-fatty-acid diet and to 12.8 percent on the saturated-fat diet. It was replaced by energy from either trans fatty acids specifically, elaidic acid and its positional isomers or saturated fatty acids alone.

The changes in the fatty-acid composition of the erythrocyte membranes during the three dietary periods confirmed the subjects' adherence to the diets. The mean $( \pm S D)$ percentage of cis-G18:1 was $13.2 \pm 0.8$ on the oleic acid diet, $11.6 \pm 0.8$ on the transfatty-acid diet, and 12.1 \pm 0.8 on the saturated-fat diet. These values are significantly different from each other $(\mathrm{P}<0.0001$ for each comparison). The mean percentage of trans-C18: 1 was $0.9 \pm 0.3$ on the oleic acid and the saturated-fat diets and $2.6 \pm 0.5$ on the transfatty-acid diet $(\mathrm{P}<0.0001)$.

As compared with its level on the oleic acid diet (Table 3), the serum total cholesterol value was 0.26 mmol per liter (10 $\mathrm{mg}$ per deciliter) higher on the trans-fatty-acid diet $(\mathrm{P}<0.0001 ; 95$ percent confidence interval, 0.17 to $0.35 \mathrm{mmol}$ per liter) and $0.54 \mathrm{mmol}$ per liter $(21 \mathrm{mg}$ per deciliter) higher on the saturatedfat diet $(\mathrm{P}<0.0001 ; 95$ percent confidence interval, 0.45 to $0.63 \mathrm{mmol}$ per liter). The difference between

Table 2. Mean Daily Intake of Energy and Nutrients of Subjects on the Oleic Acid Diet, the Trans-Fatty-Acid Diet, and the Saturated-Fat Diet.*

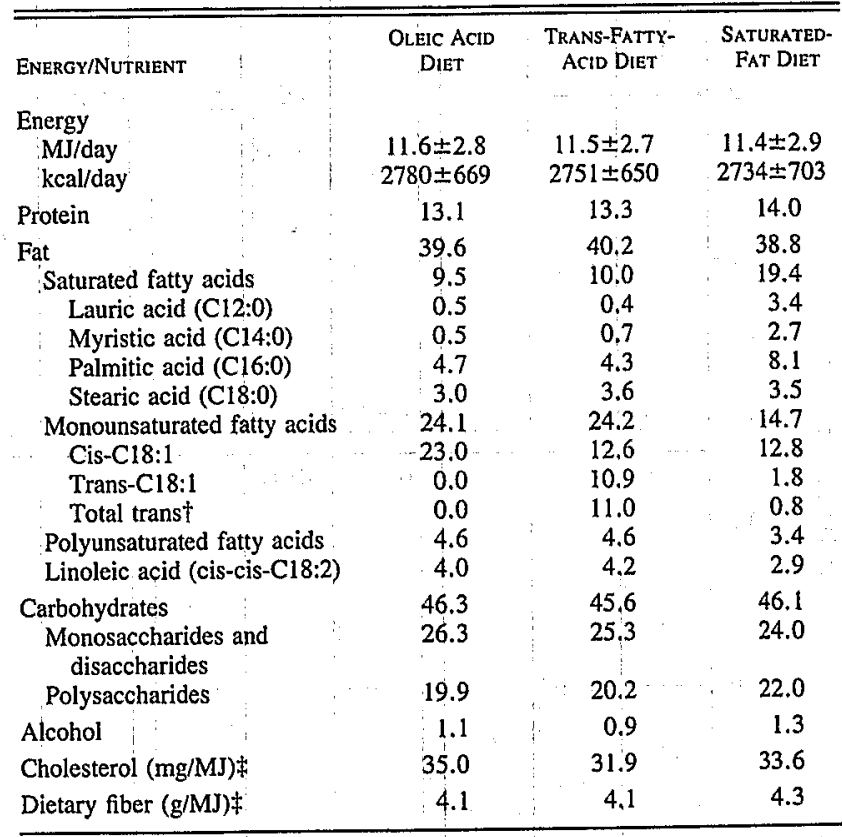

*Unless otherwise indicated, values are expressed as percentages of total daily energy intake. Values are based on chemical analyses of duplicate diets plus the calculated contribution of Values are based on chetich free-choice liens (see Methods). Each value represents the mean of theefiferes in dienry during which each diet was consumed by one thind of the subjects. Differences in dictary composition between periods and between subjects were negligible, and standard deviations are therefore not given. Specially prepared experimental fats (Table 1) provided 25 percent of the total fat intake in the oleic acid diet, 65 percent in the trans-fatty-acid diet, and 39 percent in the saturated-fat diet.

tDetermined by infrared spectroscopy and expressed in terms of elaidic acid. ${ }^{17}$ Trans fatty TDetermined by infrared spectroscopy and expressed in terms of elaidic acid the in the transacids in the saturated-fat diet were largely derived from milk and cheese; those in fat.

$\ddagger$ To convert values to amounts per $1000 \mathrm{kcal}$, multiply by 4.184 . 
Table 3. Serum Lipid and Lipoprotein Levels after Three Weeks of a Diet High in Oleic Acid, Trans Monounsaturated Fatty Acids, or Saturated Fatty Acids.*

\begin{tabular}{|c|c|c|c|c|c|c|}
\hline $\begin{array}{c}\text { LIPID/ } \\
\text { LIPOPROTEIN }\end{array}$ & $\begin{array}{l}\text { OLEIC ACID } \\
\text { DIET }\end{array}$ & $\begin{array}{l}\text { Trans-FatTY- } \\
\text { AcID Diet }\end{array}$ & $\begin{array}{l}\text { SATURATED } \\
\text { FAT DIET }\end{array}$ & \multicolumn{3}{|c|}{$\begin{array}{c}\text { P VALUES FOR } \\
\text { COMPARISON }{ }^{\dagger}\end{array}$} \\
\hline & & & & $\begin{array}{c}\text { OLEIC } \\
\text { ACID } \\
\text { VS. } \\
\text { TRANS FA }\end{array}$ & $\begin{array}{l}\text { OLEIC } \\
\text { ACID } \\
\text { VS. } \\
\text { SAT FA }\end{array}$ & $\begin{array}{c}\text { TRANS FA } \\
\text { VS. } \\
\text { SAT FA }\end{array}$ \\
\hline$:$ & \multicolumn{3}{|c|}{ mmol per liter } & & & \\
\hline \multicolumn{7}{|l|}{ Total cholesterol } \\
\hline Men & $4.23 \pm 0.72$ & $4.47 \pm 0.77$ & $4.79 \pm 0.82$ & $<0.0001$ & $<0.0001$ & $<0.0001$ \\
\hline Women & $4.63 \pm 0.57$ & $4.90 \pm 0.64$ & $5.15 \pm 0.59$ & $<0.0001$ & $<0.0001$ & $<0.0001$ \\
\hline All & $4.46 \pm 0.66$ & $4.72 \pm 0.72$ & $5.00 \pm 0.71$ & $<0.0001$ & $<0.0001$ & $<0.0001$ \\
\hline \multicolumn{7}{|l|}{ LDL cholesterol } \\
\hline Men & $2.59 \pm 0.61$ & $2.93 \pm 0.65$ & $3.05 \pm 0.66$ & $<0.0001$ & $<0.0001$ & 0.0086 \\
\hline Women & $2.73 \pm 0.48$ & $3.12 \pm 0.58$ & $3.20 \pm 0.50$ & $<0.0001$ & $<0.0001$ & 0.0997 \\
\hline All & $2.67 \pm 0.54$ & $3.04 \pm 0.61$ & $3.14 \pm 0.57$ & $<0.0001$ & $<0.0001$ & $<0.0001$ \\
\hline \multicolumn{7}{|l|}{ HDL cholesterol } \\
\hline Men & $1.24 \pm 0.29$ & $1.10 \pm 0.23$ & $1.28 \pm 0.28$ & $<0.0001$ & 0.0544 & $<0.0001$ \\
\hline Women & $1.55 \pm 0.32$ & $1.37 \pm 0.27$ & $1.53 \pm 0.31$ & $<0.0001$ & 0.5411 & $<0.0001$ \\
\hline All & $1.42 \pm 0.32$ & $1.25 \pm 0.29$ & $1.42 \pm 0.32$ & $<0.0001$ & 0.5293 & $<0.0001$ \\
\hline \multicolumn{7}{|l|}{ Triglycerides } \\
\hline Men & $0.86 \pm 0.42$ & $0.99 \pm 0.50$ & $1.00 \pm 0.63$ & 0.0267 & 0.0379 & 0.8807 \\
\hline Women & $0.78 \pm 0.29$ & $0.91 \pm 0.30$ & $0.91 \pm 0.32$ & $<0.0001$ & $<0.0001$ & 0.9613 \\
\hline All & $0.81 \pm 0.35$ & $0.94 \pm 0.40$ & $0.94 \pm 0.47$ & $<0.0001$ & $<0.0001$ & 0.8680 \\
\hline
\end{tabular}

*Plus-minus values are means $\pm \mathrm{SD}$. The 25 men and 34 women were on the diets for three weeks each in random To convert values for total, HDL, and LDL cholesierol to milligrms per deciliter, multiply by 38.67 . To conven valus triglycerides to milligrams per deciliter, multiply by 88.54

TFA denotes fatty acids, and SAT saturated

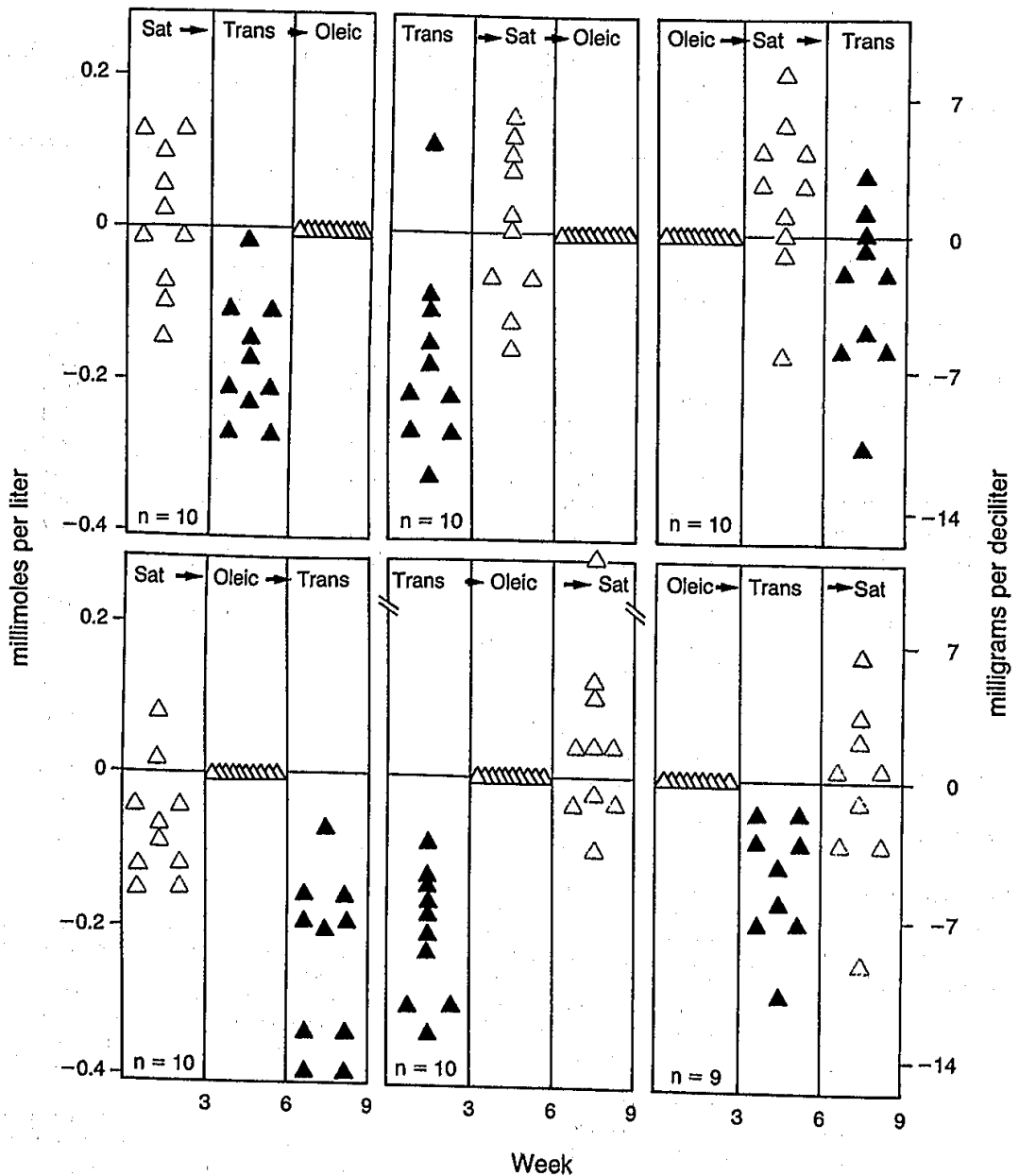

the trans-fatty-acid diet and the saturated-fat diet of $0.28 \mathrm{mmol}$ per liter (11 mg per deciliter) was also significant $(\mathrm{P}<0.0001 ; 95$ percent confidence interval, 0.18 to 0.37 mmol per liter). As compared with its level on the oleic acid diet, HDL cholesterol was $0.17 \mathrm{mmol}$ per liter ( $7 \mathrm{mg}$ per deciliter) lower on the trans-fatty-acid diet $(\mathrm{P}<0.0001 ; 95$ percent confidence interval, 0.13 to $0.20 \mathrm{mmol}$ per liter); the level was the same on the saturated-fat and oleic acid diets. The HDL cholesterol-lowering effect of trans fatty acids was evident in each of the six diet groups and in 54 of the 59 subjects (Fig. 2). The changes in apolipoprotein A-I levels paralleled those in HDL cholesterol (Table 4). The LDL cholesterol level was 0.37 mmol per liter (14 mg per deciliter) higher on the trans-fatty-acid diet $(\mathrm{P}<0.0001 ; 95$ percent confidence interval, 0.28 to $0.45 \mathrm{mmol}$ per liter) and $0.47 \mathrm{mmol}$ per liter $(18 \mathrm{mg}$ per deciliter) higher on the saturated-fat diet $(\mathrm{P}<0.0001 ; 95$ percent confidence interval, 0.39 to 0.55 mmol per liter) than on the oleic acid diet (Table 3 and Fig. 3). The plasma apolipoprotein $B$ level was highest on the trans-fatty-acid diet and lowest on the oleic acid diet (Table 4). The ratio of LDL to HDL cholesterol levels was $2.02 \pm 0.76$ on the oleic acid diet, $2.58 \pm 0.94$ on the trans-fatty-acid diet, and $2.34 \pm 0.79$ on the saturated-fat diet; all three values are significantly different from each other $(\mathrm{P}<0.0001$ for each comparison). The ratio of total cholesterol to HDL cholesterol levels increased from $3.31 \pm 0.92$ on the oleic acid diet to $3.96 \pm 1.19$ on the trans-fatty-acid diet and to $3.68 \pm 1.00$ on the

Figure 2. Individual Changes in Serum HDL Cholesterol Levels on a Diet High in Trans Fatty Acids (Trans) or Saturated Fatty Acids (Sat), as Compared with a Diet High in Oleic Acid.

Each point denotes the HDL cholesterol level of a subject on a particular diet minus his or her level when consuming the diet high in oleic acid. Each subject was on each diet for three weeks in random order. 
saturated-fat diet. These values are also significantly different from each other $(\mathrm{P}<0.0001)$. The ratio of apolipoprotein A-I to apolipoprotein $B$ levels was $1.46 \pm 0.32$ on the oleic acid diet, $1.19 \pm 0.27$ on the trans-fatty-acid diet, and $1.32 \pm 0.31$ on the saturated-fat diet. These values are significantly different from each other $(\mathrm{P}<0.0001)$. The level of triglycerides was 0.13 mmol per liter (12 $\mathrm{mg}$ per deciliter) higher on both the trans-fatty-acid and saturated-fat diets than on the oleic acid diet $(\mathrm{P}<0.0001$; 95 percent confidence interval, 0.06 to $0.20 \mathrm{mmol}$ per liter).

The ratio of apolipoprotein $B$ to LDL cholesterol levels was $356 \pm 40$ on the oleic acid diet, $357 \pm 48$ on the trans-fatty-acid diet, but $334 \pm 35$ on the saturated-fat diet, which was significantly lower $(\mathrm{P}<0.0001)$ than the other two values. The ratio of apolipoprotein A-I to HDL cholesterol levels was $965 \pm 129$ on the oleic acid diet and $960 \pm 112$ on the saturated fat diet, and it increased to $1009 \pm 127$ on the trans-fatty-acid diet; this value was significantly higher than the other two ratios $(P<0.0001)$.

All these effects were observed to a similar extent in men and women. In addition, the responses to the various diets did not differ between the 8 women using oral contraceptives and the other 26 women.

\section{Discussion}

The few previous studies that specifically examined the effects of trans fatty acids on total serum cholesterol levels yielded conflicting results. Mattson et al. ${ }^{11}$ did not find a hypercholesterolemic effect of trans-G18:1 as compared with oleic acid. Studies by Vergroesen ${ }^{9}$ and Vergroesen and Gottenbos, ${ }^{10}$ however, suggested that trans isomers of oleic acid have a cholesterol-raising effect, although it is less strong than that of saturated fatty acids. The present study confirmed this report: we found that trans fatty acids were hypercholesterolemic as compared with oleic acid and that their effect was about half that of a
Table 4. Plasma Apolipoprotein A-I and Apolipoprotein B Levels after Three Weeks of a Diet High in Oleic Acid, Trans Monounsaturated Fatty Acids, or Saturated Fatty Acids.*

\begin{tabular}{|c|c|c|c|c|c|c|}
\hline APOLIPOPROTEIN & $\begin{array}{l}\text { OLBiC ACID } \\
\text { DIET }\end{array}$ & $\begin{array}{l}\text { TRANS-FATTY- } \\
\text { AIID DiET }\end{array}$ & $\begin{array}{l}\text { SATURATED- } \\
\text { FAT DiET }\end{array}$ & $\therefore$ & $\begin{array}{l}\text { P VALUES FOR } \\
\text { COMPARISON }\end{array}$ & \\
\hline & & & & $\begin{array}{l}\text { OLEEC } \\
\text { ACID }\end{array}$ & $\begin{array}{l}\text { OLEIC } \\
\text { ACID }\end{array}$ & TRANS FA \\
\hline$\because$ & & & & vs. & vs. & \\
\hline$\therefore \quad:$ & & : & $\ldots$ & TRANS FA & SAT FA & SAT FA \\
\hline & $\therefore$ & mg per liter & & & & \\
\hline \multicolumn{7}{|l|}{ Apolipoprotein A-I } \\
\hline Men & $1204 \pm 160$ & $1129 \pm 154$ & $1247 \pm 186$ & 0.0002 & 0.0474 & $<0.0001$ \\
\hline Women & $1423 \pm 173$ & $1313 \pm 178$ & $1407 \pm 179$ & $<0.0001$ & 0.3354 & $<0.0001$ \\
\hline All & $1330 \pm 199$ & $1235 \pm 191$ & $1339 \pm 197$ & $<0.0001$ & 0.5188 & $<0.0001$ \\
\hline \multicolumn{7}{|l|}{ Apólipoprotein B } \\
\hline Men & $934 \pm 214$ & $1069 \pm 237$ & $1030 \pm 247$ & $<0.0001$ & $<0.0001$ & 0.0392 \\
\hline Women & $944 \pm 1.18$ & $1073 \pm 156$ & $1055 \pm 141$ & $<0.0001$ & $<0.0001$ & 0.2025 \\
\hline All & $940 \pm 164$ & $1071 \pm 193$ & $1045 \pm 192$ & $<0.0001$ & $<0.0001$ & 0.0169 \\
\hline
\end{tabular}

*Plus-minus values are means \pm SD. The 25 men and 34 women were on the diets for three weeks each in random order. TFA denotes fatty acids, and SAT saturated.

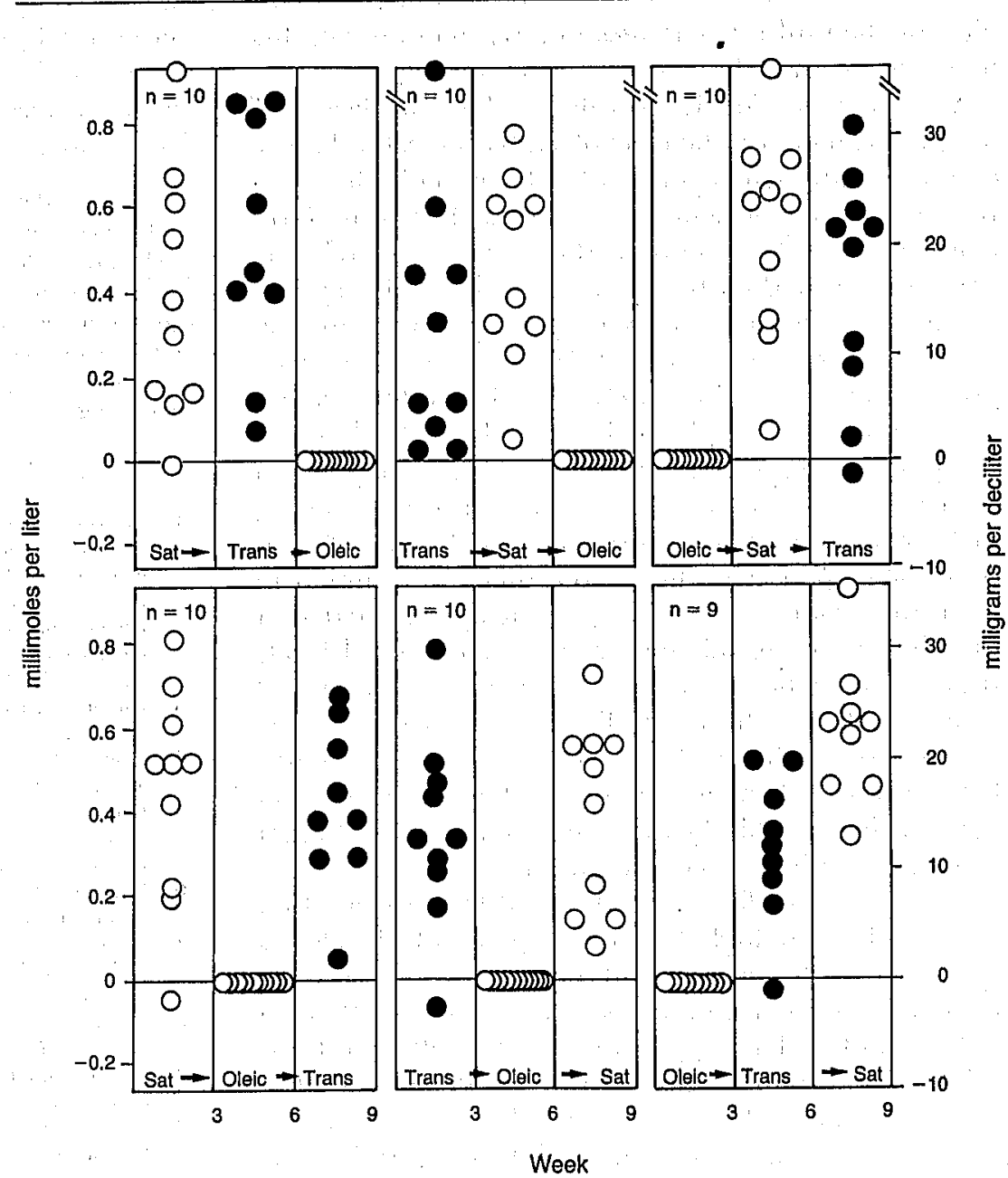

Figure 3. Individual Changes in Serum LDL Cholesterol Levels on a Diet High in Trans Fatty Acids (Trans) or Saturated Fatty Acids (Sat), as Compared with a Diet High in Oleic Acid.

Each point denotes the LDL cholesterol level of a subject on a particular diet minus his or her level when consuming the diet high in oleic acid. Each subject was on each diet for three weeks in random order. 
mixture of saturated fatty acids (lauric, myristic, and palmitic acid). However, the effect of trans fatty acids on the lipoprotein risk profile was more unfavorable than is suggested by the small increase in the serum total cholesterol concentration. The level of LDL cholesterol was higher, but the level of HDL cholesterol was lower, and as a result the ratio of LDL to HDL cholesterol was even higher on the trans-fatty-acid diet than on the saturated-fat diet. Laine et al. ${ }^{25}$ studied the effects of lightly hydrogenated soybean oil on serum lipoprotein levels in healthy men and women. They found that, as compared with hydrogenated soybean oil, unhydrogenated soybean oil decreased LDL cholesterol levels by $0.52 \mathrm{mmol}$ per liter. The level of saturated fatty acids was the same in the two diets, but the intake of polyunsaturated fat as a percentage of total energy intake was 7 percent lower and the intake of trans fatty acids 3 percent higher on the hydrogenated soybean-oil diet. The hydrogenated oil did not decrease HDL cholesterol levels in that study, ${ }^{25}$ but in view of the multiple changes in fatty-acid intake, this does not necessarily contradict our finding.

We have previously postulated that all classes of fatty acids increase the level of HDL cholesterol more or less equally when substituted for carbohydrates in the diet. ${ }^{26}$ The present study shows that trans fatty acids may be an exception; the replacement of oleic acid or saturated fat by trans fatty acids as 10 percent of total energy intake decreased HDL cholesterol levels by $0.17 \mathrm{mmol}$ per liter (Table 3), which is even greater than the decline in HDL cholesterol levels that occurs after fat is replaced by carbohydrates. ${ }^{13}$

Apolipoprotein B levels were somewhat higher on the trans-fatty-acid diet than on the saturated-fat diet, but considerably lower on the oleic acid diet. In addition, the responses to the various diets were similar in men and women. We have previously reported that men had a greater change in HDL cholesterol levels than women when saturated fatty acids were removed from the diet. ${ }^{2}$ The main difference was that in the present study, the level of stearic acid did not change between the oleic acid and the high-saturated-fat diets. Whether this factor may explain the different results needs further investigation.

Both the trans-fatty-acid diet and the saturated-fat diet resulted in higher serum triglyceride levels, as compared with the oleic acid diet. In this respect, too, results from other studies are conflicting. Mattson et al. ${ }^{11}$ did not find a triglyceride-elevating effect of trans relative to cis monounsaturates. Anderson et al., ${ }^{27}$ however, found that triglyceride levels were higher when subjects were on a diet high in trans isomers of monounsaturated and polyunsaturated fatty acids than when they were on a diet high in butterfat.

The average consumption of trans fatty acids in the United States is 2 to 4 percent of daily energy intake. Linear extrapolation from the results of the present study would suggest that replacing all trans fatty acids in the diet with oleic acid might increase the level of
HDL cholesterol by an average of $0.05 \mathrm{mmol}$ per liter (1.8 mg per deciliter) and decrease the level of LDL cholesterol by $0.10 \mathrm{mmol}$ per liter $(3.9 \mathrm{mg}$ per deciliter). We do not know, however, whether the effect of trans fatty acids on the levels of HDL and LDL cholesterol is proportional to intake. In addition, we have specifically examined trans fatty acids with 18 carbon atoms and one double bond, the most important class of fatty acids in the diet. ${ }^{7}$ We do not know whether our results can be extended to trans fatty acids with a higher number of carbon atoms, such as those formed when fish oil is hydrogenated. Our findings do not even apply unreservedly to all hydrogenated fats and oils rich in trans fatty acids with 18 carbon atoms and one double bond. Although the spectrum of trans fatty acids in our experimental diet was quite similar to that in hydrogenated soybean oil ${ }^{28}$ - the major source of trans fatty acids in the American diet - subtle but important differences in composition might exist between the hydrogenated fat we used and that used in actual food production. Nevertheless, for the time being it would seem prudent for patients at increased risk of atherosclerosis to avoid a high intake of trans fatty acids.

We are indebted to the members of our technical and dietary staff, especially Mrs. Jeanne H.M. de Vries, R.D., and Mr. Peter L. Zock, M.Sc., for their help and advice; to the subjects for their cooperation and interest; to Dr. E.A. Emken, U.S. Department of Agriculture, for the analysis of positional isomers in the margarines; and to Unilever Research Laboratory, Vlaardingen, the Netherlands, for developing and manufacturing the special margarines and shortenings.

\section{REFERENCES}

1. Mattson FH, Grundy SM. Comparison of effects of dietary saturated, monounsaturated, and polyunsaturated fatty acids on plasma lipids and lipoproteins in man. J Lipid Res 1985; 26:194-202.

2. Mensink RP, Katan MB. Effect of a diet enriched with monounsaturated or polyunsaturated fatty acids on levels of low-density and high-density lipoprotein cholesterol in healthy women and men. N Engl J Med 1989; 321:436-41.

3. Parodi PW. Distribution of isomeric octadecenoic fatty acids in milk fat. J Dairy Sci 1976; 59:1870-3.

4. Slover HT, Thompson RH Jr, Davis CS, Merola GV. Lipids in margarines and margarine-like foods. J Am Oil Chem Soc 1985; 62:775-86.

5. Enig MG, Pallansch LA, Sampugna J, Keeney M. Fatty acid composition of the fat in selected food items with emphasis on trans components. J Am Oil Chem Soc 1983: 60:1788-95.

6. Wiedermann LH. Margarine and margarine oil, formulation and control. $\mathrm{J}$ Am Oil Chem Soc 1978: 55:823-9.

7. Senti FR, ed. Health aspects of dietary trans fatty acids: August 1985. Bethesda, Md.: Federation of American Societies for Experimental Biology, 1988. (Contract no. FDA 223-83-2020.)

8. Brussaard JH. Hoeveel transvetzuren bevat de Nederiandse voeding? Voeding $1986 ; 47: 108-11$.

9. Vergroesen AJ. Dietary fat and cardiovascular disease: possible modes of action of linoleic acid. Proc Nutr Soc 1972; 31:323-9.

10. Vergroesen AJ, Gottenbos JJ. In: Vergroesen $A J$, ed. The role of fats in human nutrition. New York: Academic Press, 1975:1-41.

11. Mattson FH, Hollenbach EJ, Kligman AM. Effect of hydrogenated fat on the plasma cholesterol and triglyceride levels of man. Am J Clin Nutr 1975: 28:726-31.

12. Brussaard JH, Katan MB, Groot PHE, Havekes LM, Hautvast JGAJ. Serun! lipoproteins of healthy persons fed a low-fat diet or a polyunsaturated fat diet for three months: a comparison of two cholesterol-lowering diets. Atherosclerosis 1982; 42:205-19.

13. Mensink RP. Katan MB. Effect of monounsaturated fatty acids versus complex carbohydrates on high-density lipoproteins in healthy men and women. Lancet 1987; 1:122-5. 
14. Snedecor GW; Cochran WG, Statistical methods. 7th ed. Ames: Iowa State University Press, 1980.

15. SAS Institute Inc. SAS user's guide: statistics, version 5 edition. Cary, N.C.: SAS Institute, 1985.

16. Kommissie UCV. UCV tabel: uitgebreide voedingsmiddelen tabel 1985. the Hague, the Netherlands: Voorlichtingsbureau voor de Voeding, 1985:

17. Williams $\mathrm{S}$; ed. Official methods of analysis of the Association of Official Analytical Chemists: 14th ed. Arlington, Va.: AOAC, 1984.

18. Warnick GR, Benderson J, Albers JJ. Dextran sulfate-Mg2 + precipitation procedure for quantitation of high-density-lipoprotein cholesterol. Clin Chem 1982; 28:1379-88.

19. Sullivan DR, Kruijswijk Z, West CE, Kohlmeier M, Katan MB, Determination of serum triglycerides by an accurate enzymatic method not affected by free glycerol. Clin Chem 1985; 31:1227-8.

20. Warnick GR, Clapshaw' P. Availability of plasma with target values for certain lipids. Clin Chem 1987; 33:2323-4.

21. Friedewald WT, Levy RI, Fredrickson DS. Estimation of the concentration of low-density lipoprotein cholesterol in plasma, without use of the preparative ultracentrifuge. Clin Chem 1972; 18:499-502.
22. Glatz JF, Soffers AE; Katan MB. Fatty acid composition of serum cholesteryl esters and erythrocyte membranes as indicators of linoleic acid intake in man. Am J Clin Nutr 1989; 49:269-76.

23. Irish GR, Ledue TB, Barrantes DM. Measurement of apolipoprotein A-I in serum with the Technicon RA-1000 system. Clin Chem 1987; 33:1266.

24. Mensink RP, de Groot MJ, van den Broeke LT, Severijnen-Nobels AP, Demacker PN; Katan MB. Effects of monounsaturated fatty acids $v$ complex carbohydrates on serum lipoproteins and apoproteins in healthy men and women. Metabolism 1989; 38:172-8:

25. Laine DC, Snodgrass CM, Dawson EA, Ener MA, Kuba K, Frantz ID Jr. Lightly hydrogenated soy oil versus other vegetable oils as a lipid-lowering dietary constituent. Am J Clin Nutr 1982; 35:683-90.

26. Katan MB. Diet and HDL. In: Miller NE, Miller GJ, eds. Clinical and metabolic aspects of high-density lipoproteins. Vol. 3 of Metabolic aspects of cardiovascular disease. 'Amsterdam:'Elsevier, 1984:103-31.

27. Anderson JT, Grande F, Keys A. Hydrogenated fats in the diet and lipids in the serum of man. J Nutr 1961; 75:388-94

28. Sampugna J, Pallansch LA, Enig. MG, Keeney M. Rapid analysis of trans fatty acids on SP-2340 glass capillary columns. J Chromatogr 1982; 249:245-55.

\title{
LACK OF EFFICACY OF HYDERGINE IN PATIENTS WITH ALZHEIMER'S DISEASE
}

\author{
Troy L. Thompson II, M.D., Christopher M. Filley, M.D., Wayne D. Mitchell, Ph.D., \\ Kathleen M. Culig, B.S.N., A.N.P., Mary LoVerde, M.S.N., A.N.P., \\ AND Richard L. Byyny, M.D.
}

\begin{abstract}
Background: There is no effective pharmacologic treatment for Alzheimer's disease, the most common dementing illness in the United States. Hydergine, a combination of ergoloid mesylates, is the only approved medication for Alzheimer's disease, but despite widespread use its efficacy remains to be established. We conducted a clinical trial of Hydergine-LC, a newer preparation of ergoloid mesylates in the form of a liquid in a capsule (LC) that may have greater bioavailability, to determine its value in patients with Alzheimer's disease.

Methods and Results. Eighty'older adults with probable Alzheimer's disease participated in this double-blind, placebo-controlled trial of Hydergine-LC for 24 weeks. The
\end{abstract}

ALZHEIMER'S disease is the most common dementing illness and may be the fourth leading cause of death in the United States. It severely affects about 1.4 million Americans, and this number is predicted to increase fivefold in the next half century. ${ }^{1-4}$ The current direct and indirect annual cost of Alzheimer's disease in the United States is estimated to be $\$ 24$ billion to $\$ 48$ billion. ${ }^{4,5}$ The disease has no known cause or effective treatment, although a wide variety of therapeutic approaches have been considered. ${ }^{6}$ One medication used for Alzheimer's disease is Hydergine (Sandoz brand of ergoloid mesylates), a preparation containing $0.333 \mathrm{mg}$ each of dihydroergocornine mesylate, dihydroergocristine mesylate, and dihydro-

From the Departments of Psychiatry (C.M.F.), Medicine (W.D.M., K.M.C., M.LoV,, R.L.B.), and Neurology (C.M.F.), University of Colorado School of Medicine, Denver; and the Department of Psychiatry, Jefferson Medical College, Philadelphia (T.L.T.). Address reprint requests to Dr. Thompson at the Department of Psychiatry, Jefferson Medical College, 1015 Walnut St., Philadelphia, PA 19107.

Supported by a grant from Sandoz Research Institute. recommended dose of $1 \mathrm{mg}$ orally three times daily was used. Cognition and behavior were evaluated before and after the trial, and the patients were monitored for adverse effects. The medication was safe and well tolerated. The Hydergine-LC group did not perform better after treatment than the placebo group on any test, and its performance was worse $(P<0.01$ and $P<0.02$, respectively) on one cognitive measure (Wechsler Adult Intelligence Scale Digit Symbol Substitution Task) and on one behavioral scale (the Geriatric Evaluation by Relatives Rating Instrument).

Conclusions. Hydergine-LC appears to be ineffective as a treatment for Alzheimer's disease. ( $N$ Engl $J$ Med 1990; 323:445-8.)

ergocryptine mesylate, the last of which consists of dihydro- $\alpha$-ergocryptine mesylate and dihydro- $\beta$-ergocryptine mesylate in a proportion of 2:1. In 1984, Hydergine was the 11 th most widely prescribed drug in the world, ${ }^{7}$ and it is the only medication approved by the Food and Drug Administration for Alzheimer's disease. Initially thought to act as a cerebral vasodilator, Hydergine is now considered to be a metabolic enhancer, because it may improve some aspects of neuronal metabolism and neurotransmitter activity. ${ }^{8}$

Although more than 20 double-blind, placebo-controlled trials have shown favorable results with ergoloid mesylates, many clinicians remain skeptical of its efficacy; uncertainties persist about placebo responses, the heterogeneity of study groups, and the clinical importance of the observed beneficial effects. ${ }^{7}$ Hydergine-LC, a newer preparation of ergoloid mesylates, delivers the drug as a liquid in a capsule (LC), a form that may have greater bioavailability. ${ }^{9}$ To test the safety and efficacy of this new formulation, we conducted a double-blind, placebo-controlled trial of $\mathrm{Hy}$ - 